\title{
THE PROBLEM OF COMPATIBILITY AND INTEROPERABILITY OF SATELLITE NAVIGATION SYSTEMS IN COMPUTATION OF USER'S POSITION
}

\author{
Jacek Januszewski \\ Gdynia Maritime University, \\ Navigation Department \\ al. JanaPawla II 3, 81-345 Gdynia, Poland \\ e-mail:jacekjot@am.gdynia.pl
}

\begin{abstract}
Actually (June 2011) more than 60 operational GPS and GLONASS (Satellite Navigation Systems - SNS), EGNOS, MSAS and WAAS (Satellite Based Augmentation Systems - SBAS) satellites are in orbits transmitting a variety of signals on multiple frequencies. All these satellite signals and different services designed for the users must be compatible and open signals and services should also be interoperable to the maximum extent possible. Interoperability definition addresses signal, system time and geodetic reference frame considerations. The part of compatibility and interoperability of all these systems and additionally several systems under construction as Compass, Galileo, GAGAN, SDCM or QZSS in computation user's position is presented in this paper. Three parameters - signal in space, system time and coordinate reference frame were taken into account in particular.
\end{abstract}

Keywords: Satellite Navigation System (SNS), Saellite Based Augmentation System (SBAS), compability, interoperability, coordinate reference frame, time reference, signal in space

\section{INTRODUCTION}

Information about user's position can be obtained from specialized electronic position-fixing systems, in particular, Satellite Navigation Systems (SNS) as GPS and GLONASS, and Satellite Based Augmentation Systems (SBAS) as EGNOS, WAAS and MSAS. All these systems are known also as GNSS (Global Navigation Satellite System). Actually (June 2011) more than 60 operational GPS, GLONASS, EGNOS, MSAS and WAAS satellites are in orbits transmitting a variety of signals on multiple frequencies. In this year GLONASS system will have Full Operational Capability (FOC) again (www.glonass-ianc.rsa.ru).

The last years gave a rise to many important changes in the operational status and practical exploitation of all these systems. New SNS as Galileo in Europe and Compass (BeiDou) in China, new SBAS as GAGAN in India and SDCM in Russia, new regional SNS as IRNSS in India and QZSS in Japan are under construction. It means that within five years the number of satellites which can be used in user's position computation will reach 90 or more, with even more types of signals broadcast on even more frequencies. All these changes, new frequencies and new signals, in particular, represent good news, but sometimes some notsuch good news also for GNSS product designers, service providers, and finally users. For 
example, recent studies indicate that more than three GNSS systems operating in the same band can cause problems (Gibbons, 2011). All these systems, all satellite signals and different services designed for the users must be compatible and open signals and services should also be interoperable to the maximum extent possible.

Compatibility of GNSS can be defined as ability of these systems to be used separately or together without interfering with each individual system and without adversely affecting navigation warfare. It means, that GNSS do not interfere with each other, and that nonmilitary (and non-governmental) signals can be jammed without adversely affecting those signals. Interoperability - ability of systems to be used together to provide the user better capabilities than would be achieved by relying solely on one system.

Interoperability of SNS and SBAS can be defined as ability of each of these systems having independent control loop to operate jointly with other systems without interfering each other on condition that signal frequency ranges, coordinate reference frames and time reference frame coincide as much possible (Januszewski, 2007). According to technical point of view the interoperability means the same center frequency, same modulation, commonly agreed maximum power level, geodetic reference frames realization and system time reference (www.galileo.cs.telespazio.it).

For the mariner user of GNSS ideal interoperability, called sometimes interchangeability, can be expressed as navigation with one signal each from four or more systems with no additional receiver cost or complexity (Turner, 2010).

Although common reference systems (signal, time, datum) would have facilitated the interoperability, all mentioned above SNS have been intentionally designed to use different reference frame, in order to avoid common mode failures and, thus, to increase the integrity of combined solutions (Hein, 2006).

\section{POLITICAL ACKNOWLEDGMENT}

The U.S. Government has engaged European Union and a number of other countries (Australia, China, India, Japan and Russia) and international organization - International Civil Aviation Organization (ICAO), International Maritime Organization (IMO), International Telecommunication Union (ITU) and North Atlantic Treaty Organization (NATO) in cooperative activities related to space-based PNT (Positioning, Navigation, Timing) systems. This cooperation is intended to ensure among other things compatibility and interoperability between GPS and other SNS and SBAS, and it can be presented as follows (Turner, 2010):

- Japan, 1998, Joint Statement on GPS Cooperation,

- European Union, 2004, GPS - Galileo Cooperation Agreement,

- Russia, 2004, Joint Statement, GPS - GLONASS cooperation,

- India, 2007, Joint Statement on GNSS Cooperation,

- China, 2007, operator-to-operator coordination under ITU auspices,

- Australia, 2007, Joint Delegation Statement on Cooperation in the Civil Use.

The problem of compatibility and interoperability between Galileo and other SNS and between EGNOS and other SBAS is the theme of regular meeting between EU and a number of other countries (table 1) (www.galileo.cs.telezpazio.it).

Federal GLONASS program is a basis for GLONASS state policy implementation. Additionally GLONASS providers use cooperation with China, India (deployment support, augmentations interoperability), former USRR countries (Kazakhstan in particular), Middle East, Australia and Latin America (www.glonass-ianc.rsa.ru). 
Table 1. The discussion between European Union and other countries about compatibility and interoperability of Satellite Navigation Systems (SNS) and Satellite Based Augmentation Systems (SBAS)

\begin{tabular}{||c|c||}
\hline Country & Compatibility and interoperability \\
\hline \hline China & Compass with Galileo \\
\hline India & IRNSS with Galileo and GAGAN with EGNOS \\
\hline Japan & QZSS with Galileo, good prospect for on E6CS/QZSSLex interoperable signal \\
\hline Russian Federation & GLONASS with Galileo and SDCM with EGNOS \\
\hline United States & $\begin{array}{c}\text { GPS with Galileo, common MBOC civil signal } \\
\text { on GPS L1C - Galileo E1 Open Service }\end{array}$ \\
\hline
\end{tabular}

\section{SIGNAL IN SPACE}

Actually (June 2011) all three frequencies GPS satellites differ from two GLONASS frequency bands. Only in the future the same frequencies carrier will be common for two or more SNS. The current and future frequencies carrier of GPS, Galileo, Compass, GLONASS (satellites K1, K2 and later using format CDMA only), EGNOS, WAAS, MSAS and QZSS are presented in the table 2. According to this table in the theme of interoperability of all mentioned above SNS and SBAS in the future we can say that (www.gpsworld.com), (www.insidegnss.com):

Table 2. Satellite Navigation Systems (SNS), Satellite Based Augmentation Systems (SBAS), current and future frequencies carrier

\begin{tabular}{|c|c|c|c|c|}
\hline \multirow{2}{*}{ System } & \multicolumn{4}{|c|}{ Frequency [MHz] } \\
\hline & $\begin{array}{l}1176.45 \\
\text { (L5 band) }\end{array}$ & 1207.14 & $\begin{array}{c}1227.60 \\
\text { (L2 band) }\end{array}$ & $\begin{array}{c}1575.42 \\
\text { (L1 band) }\end{array}$ \\
\hline GPS & L5 (satellites IIF) & - & L2 & L1 (all satellites) \\
\hline Galileo & E5a & $\mathrm{E} 5 \mathrm{~b}$ & - & E2-L1-E1 \\
\hline $\begin{array}{c}\text { GLONASS } \\
\text { (block K and later) }\end{array}$ & - & L3 & - & - \\
\hline $\begin{array}{c}\text { GLONASS } \\
\text { (block KM and later) }\end{array}$ & L5 & L3 & - & - \\
\hline Compass & $\mathrm{B} 2 \mathrm{a}$ & $\mathrm{B} 2 \mathrm{~b}$ & - & $\mathrm{B} 1 \mathrm{C}, \mathrm{B} 1 \mathrm{~A}$ \\
\hline $\begin{array}{l}\text { SBAS (EGNOS, } \\
\text { WAAS, MSAS) }\end{array}$ & $\begin{array}{l}\text { L5 - WAAS } \\
\text { (in the future) }\end{array}$ & - & - & L1 \\
\hline QZSS & L5 & - & L2 & L1 \\
\hline
\end{tabular}


- GPS and Galileo will have "signal interoperable" with regard to the L1/E2-L1-E1 frequency (1575.42 MHz) and L5/E5a frequency (1176.45 MHz), and both (open and free) services (SPS and OS),

- QZSS plans to be "signal interoperable" to GPS and Galileo on the same three frequencies (L1, L2, L5). Since October 2010 a new L1C signal is broadcasted by QZSS Michibiki, the first satellite in history to transmit L1C. This signal is designed to be interoperable among GNSS. The QZSS L1C ranging codes and navigation messages are in accordance to the codes and messages envisioned for the GPS L1C signals. The QZSS L2C will be a replica of GPS L2C and similarly the QZSS L5I and L5Q signals will be a replica of the GPS L5C. GPS system is not destined to add the L1C signal until the GPS III block of satellites (the first satellite in orbit in 2014),

- the military GPS M-code and the Galileo Public Regulated Service (PRS) will have "signal interoperability" on L1,

- the future L3 (1207.14 MHz) frequency of GLONASS satellites block K and later (format CDMA) can be operable with E5b frequency of Galileo system and B2b of Compass system,

- the future L5 (1176.45 MHz) frequency of GLONASS satellites block KM and later (format CDMA) can be interoperable with the L5 frequency of GPS system and B2a of Compass system.

The signals characteristics to be transmitted by GPS, Galileo and Compass satellites in the Lband, carrier frequency $1575.42 \mathrm{MHz}$, is showed in the table 3 . All these 8 signals must be taken into account in the simulation and analysis.

Table 3. GPS, Galileo and Compass signal parameters on the L1 band

\begin{tabular}{|c|c|c|c|}
\hline System & Signal, code & Modulation type & Chip rate [Mcps] \\
\hline \multirow{4}{*}{ GPS } & $\mathrm{C} / \mathrm{A}$ & BPSK & 1.023 \\
\hline & $\mathrm{P}(\mathrm{Y})$ & BPSK & 10.23 \\
\hline & $\mathrm{M}$ & $\operatorname{BOC}(10,5)$ & 5.115 \\
\hline & $\mathrm{L} 1 \mathrm{C}$ & $\operatorname{MBOC}(6,1,1 / 11)$ & 1.023 \\
\hline \multirow{2}{*}{ Galileo } & L1 OS & $\operatorname{MBOC}(6,1,1 / 11)$ & 1.023 \\
\hline & L1 PRS & $\mathrm{BOC} \cos (15,25)$ & 2.5575 \\
\hline \multirow{2}{*}{ Compass } & $\mathrm{B} 1 \mathrm{C}$ & $\operatorname{MBOC}(6,1,1 / 11)$ & 1.023 \\
\hline & $\mathrm{B} 1 \mathrm{~A}$ & $\operatorname{Boc}(14,2)$ & 2.046 \\
\hline
\end{tabular}

BPSK - Binary phase-shifted key, BOC - Binary offset carrier, MBOC - Multiplexed binary offset carrier

The different SNS have been designed to be compatible. Therefore the signals have been specified to be in common between the system, nevertheless same signals have intentionally been separated to avoid common mode failures (Hofmann-Wellenhof B. et al., 2008). In the case of integrated receivers (two SNS at least) an increasing number of observations (e.g. 
pseudoranges), but this does not obligatory decrease the DOP coefficient values and increase the position's accuracy.

In SNS applications it is required to broadcast multiple signals from a satellite constellation, from a single satellite, and even upon a single carrier frequency. There are a number of techniques to facilitate this sharing of a common transmission channel without the broadcast signals interfering with each other. Nowadays two techniques are used:

- different spreading codes to allow the sharing of a common carrier - CDMA (Code Division Multiple Access),

- different carrier frequencies to transmit multiple signals - FDMA (Frequency Division Multiple Access).

It means that each GPS satellite, all blocks, transmits a unique PRN code on the same frequency in a CDMA format, and each GLONASS satellite, block M, transmit the same PRN code on a different frequency in a FDMA format. The next generation of GLONASS satellites will use CDMA format, block K1 and K2 on the third frequency L3 and block KM on L3 and additionally on the fourth frequency L5. The CDMA format will be use in two other SNS, actually under construction, Galileo and Compass also.

As we compare two techniques CDMA and FDMA we can say that the FDMA generally entails a more costly hardware realization that does the CDMA and FDMA measurements quality is generally less than in the case of CDMA. That's why as a consequence of the signal-in-space interoperability requirement (identical center frequencies of interoperable signals), only CDMA satellite systems can fulfil it, because GLONASS signal (satellites block M) is actually not "signal interoperable" to GPS signal or in the future to Galileo signal, but GLONASS system is "sys tem interoperable".

Interoperability means that the system can be combined in one receiver for a merged position and time solution better than from each system alone. New integrated receivers permit to use two or more SNS (both operational and under construction) and SBAS simultaneously. In Nottingham Scientific Ltd PRIMO II it is: GPS - L1 C/A code, Galileo E1, GLONASS - L1OC and L1OF, Compass - B1. In Trimble NetR9 it is: GPS - L1 C/A, L2C, L5; GLONASS - L1 C/A, P; L2 C/A2, P; Galileo (GIOVE-A and GIOVE-B); SBAS L1 C/A, L5), L-Band OmniSTAR (GPS Receiver Survey, 2011).

\section{TIME REFERENCES FRAME}

While most clocks in the world are synchronized to UTC (Universal Time Coordinated), the atomic clocks on the satellites are set to own SNS time.

\subsection{GPS System Time (GPST)}

GPS system uses its own particular, continuous time scale GPS System Time (GPST) referenced to UTC (US Naval Observatory - USNO). GPST differs from UTC by a nearly integer number of seconds:

$$
\mathrm{GPS}_{\text {time }}-\mathrm{UTC}=\mathrm{n} \cdot \mathrm{s}-\mathrm{C}_{\mathrm{t}}
$$

where $\mathrm{n}$ is an integer number, and the correction term $\mathrm{C}_{\mathrm{t}}$ is in the order of several nanoseconds. GPST is a continuous time scale that is not corrected to match the rotation of the Earth, so it does not contain leap seconds or other corrections which are periodically added to UTC. GPST is a paper time scale; it is based on statistically processed readings from 
atomic clocks in the satellites and at various ground control segment components (Kaplan, Hegarty, 2006), (Januszewski, 2010).

GPST and UTC(USNO) were coincident at 0h January 6, 1980. As at this moment the difference between TAI (Time Atomic Scale) and UTC was 19 seconds, GPST remains at a constant offset with TAI:

$$
\mathrm{TAI}-\mathrm{GPS}_{\mathrm{time}}=19 \text { seconds }
$$

At the time of this writing (June 2011) the difference between GPST and UTC was 15 seconds. Therefore the reception of GPS signals provides real-time access to TAI and UTC with uncertainties below 1 microsecond (Misra, Enge, 2006).

\section{2. GLONASS System Time (GLONASSST)}

GLONASS time, base on an atomic time scale similar to GPS, is strongly liked to the national time scale of Russian Federation - UTC(SU) which is maintained by the Main Metrological Center of the Russian Time and Frequency service at Mendeleevo in the Moscow region. On other hand GLONASS system itself is the most powerful and accurate mean of UTC(SU) dissemination through out Russia and the world. That is why one of requirements of GLONASS updates is to keep UTC-UTC(SU) difference within 10 ns (www.congrex.nl).

This time is generated and controlled by the GLONASS Central Synchronizer, based on a set of hydrogen masers. The relation between UTC and GLONASSST is

$$
\mathrm{UTC}=\mathrm{GLONASSST}+\tau_{\mathrm{c}}-3^{\mathrm{h}}
$$

The discrepancy, $\tau_{\mathrm{c}}$, comes from the different clock ensembles used and is communicated to the GLONASS users in the GLONASS navigation message (Seeber, 2003).

Unlike the GPS time scale, GLONASSST currently implements leap seconds, like UTC, and it has a constant offset of three hours (difference Moscow time to Greenwich time). Apart from this constatnt offset, the difference between GLONASSST and UTC shall be within 1 microsecond arising from the keeeping of the time scales by different clocks (Hofmann-Wellenhof B. et al., 2008). During the leap second correction, GLONASSST is also corrected by changing enumeration of second pulses of onboard clocks of all GLONASS satellites.

In navigation message the data concerning time are transmitted in the immediate data which include time marks and synchronization difference between satellite clock and GLONASSST, and in the non-immediate data which include raw clock corrections to this time and the GLONASS time correction relative to UTC(SU). The GLONASS satellites are equipped with cesium clocks which daily instability is not worse than $5 \cdot 10^{-13}$ (Januszewski, 2010), (Samama, 2008)

\subsection{Galileo System Time (GST)}

The Galileo System Time (GST) is a continuous atomic time scale with a nominal constant offset (integer number of seconds) with respect to TAI. With respect to UTC, the modulo 1 second offset is variable due to the insertion of leap seconds. GST will be maintained by a n ensemble of atomic frequency standards, where active hydrogen maser clocks will serve as the master clock (Hofmann-Wellenhof B. et al., 2008).

GST is specified to be kept to within $50 \mathrm{~ns}(95 \%)$ of TAI over any 1-year time interval. The offset between TAI and GST will be known with a maximum uncertain-ty of $28 \%$ ( 2 sigma), assuming the estimation of TAI six weeks in advance. Users equipped with a Galileo 
timing receiver will be able to predict UTC to $30 \mathrm{~ns}$ for $95 \%$ of any 24 hours operation (Hahn, Powers, 2004).

The data concerning the offset of GST with respect to TAI and UTC will be included in the Galileo navigation message.

\subsection{Other systems and the translation of SNS time to UTC/TAI}

Compass system will use BeiDou time (BDT), Chinese UTC maintained by atomic clocks in the control center at Beijing.

The QZSS (Quasi-Zenith Satellite System) time scale is aligned to TAI, having the same integer offset to TAI (19 seconds) as GPS system. The offset between the QZSS time scale and GPST will be emitted in the navigation message of GPS and QZSS. A similar interface is envisioned for the offset to GST (Hofmann-Wellenhof B. et al., 2008).

UTC can be obtained from GPS receiver, and in the future from Galileo receiver, by adding the integral number of leap seconds and fine UTC/TAI correction information contained in the navigation data. In order to provide an estimate of UTC from GPS, the navigation message broadcast by each GPS satellite includes estimates of the time difference between GPST and UTC(USNO) modulo one second, and its rate. The navigation message also includes the whole-second difference between the two time scales due to leap seconds. These parameters allow a receiver clock to calculate an accurate estimate UTC(USNO). The detailed relations can be found in (Januszewski, 2010), (Kaplan, Hegarty, 2006).

\section{GEODETIC COORDINATE REFERENCE FRAME}

The different coordinate reference frames influence the satellite coordinates. That's why the coordinates of user's position obtained from SNS are expressed in different geodetic datum.

World Geodetic System 1984 (WGS84) is applied for GPS system. After some modifications, the present version of WGS84 is almost identical with the latest version ITRF (International Terrestrial Reference Frame). The coordinates in GLONASS system are based on the parameter of the Earth 1990 (PE-90) frame, since September 2007 in version 90.02, also known as Parametry Zemli 1990 (PZ-90.02) frame. This version is coordinated to ITRF. Galileo system will have its own reference frame GTRF (Galileo Terrestrial Reference

Frame), Compass system - China Geodetic CoSystem 2000 (CGCS2000), which will consistent with ITRF. The GTRF is specified to differ from the latest version of ITRF by no more than 3 centimeters (Groves, 2008), (Hofmann-Wellenhof B. et al., 2008), (Misra, Enge, 2006).

It means that the problem of compatibility of SNS and as well SBAS in the case of reference frame for majority users does not exist. This problem for some users, mariners, in particular, appears when the position obtained from the receivers of these systems must be plotted on the chart.

Actually almost all ships have on their bridges navigation one GPS receiver at least, usually two, sometimes even four. As GPS position must be plotted on the paper chart or introduced to electronic chart, for all users the knowledge of geodetic datum on which this chart was published is critical. The most frequently used charts, in particular in Europe, are published by United Kingdom Hydrographic Office. On bridge navigation there are several hundred charts at least, often several thousand, but many chart are not yet referred to WGS84 geodetic datum (also known as horizontal datum). It means that, in those cases, position obtained from GPS receivers will not be directly compatible with the chart and must be used without adjustment because the differences may be significant to navigation. That's why since 
1982 the UKHO has been adding "Satellite-Derived Positions" notes to indicate the shift that needs to be applied to WGS-84 datum positions before plotting them on the chart.

As majority of the charts are referred to local or regional geodetic datum position referred to different datums can differ by several hundred meters or even more; e.g. position of South Foreland Lt in United Kingdom referred to ED50 datum differs by 133 meters from position referred to WGS-84 datum. Therefore some countries are adopting their own regional or continental equivalent of WGS-84, e.g. North American Datum (NAD83) and European Terrestrial Reference System 1989 (ETRS89), (ALRS, 2010).

In 2010 the total number of charts published by UKHO was greater than 8,000, the number of used datums was 67. The number of charts referred to 10 most frequently used geodetic datums since 2004 are presented in the table 4 . We can recognize that in this period (2004-2010):

- the total number of charts has been increased (18.1\%), as well the of charts published on WGS-84 datum (94.4\%), ETRS (130.1\%) and Pul kovo1942 System (12.8\%),

- the number of charts referred to Australian datum, Ordnance Survey of Ireland datum and with unknown datum has been decreased, adequately $51.4 \%, 54.2 \%$ and $41.1 \%$,

- since 2006 the two most frequently used datums were WGS-84 and ETRS, in 2010 it was adequately $36.1 \%$ and $18.3 \%$.

Table 4. The number of United Kingdom Hydrographic Office charts referred to different geodetic datums (ALRS, 2004-2010)

\begin{tabular}{|c|c|c|c|c|c|c|c|}
\hline \multirow{2}{*}{ Geodetic datum } & \multicolumn{7}{|c|}{ Year } \\
\hline & 2004 & 2005 & 2006 & 2007 & 2008 & 2009 & 2010 \\
\hline Australian Geodetic & 142 & 130 & 127 & 126 & 118 & 94 & 69 \\
\hline European (1950) & 817 & 778 & 686 & 572 & 547 & 497 & 481 \\
\hline ETRS 89 & 636 & 704 & 724 & 890 & 1107 & 1206 & 1467 \\
\hline $\begin{array}{c}\text { Indian Datum } \\
\text { (Survey of India) }\end{array}$ & 95 & 94 & 95 & 96 & 98 & 70 & 71 \\
\hline $\begin{array}{l}\text { North American } \\
\text { Datum (1983) }\end{array}$ & 312 & 315 & 319 & 326 & 348 & 354 & 356 \\
\hline $\begin{array}{l}\text { Ordnance Survey } \\
\text { of Ireland }\end{array}$ & 131 & 125 & 122 & 107 & 87 & 77 & 60 \\
\hline $\begin{array}{c}\text { Pulkovo } 1942 \\
\text { System }\end{array}$ & 60 & 61 & 61 & 66 & 69 & 70 & 77 \\
\hline Undetermined & 1993 & 2116 & 1997 & 1899 & 1773 & 1756 & 1667 \\
\hline WGS72 & 39 & 34 & 33 & 34 & 34 & 34 & 33 \\
\hline WGS84 & 1488 & 1813 & 2081 & 2168 & 2339 & 2766 & 2892 \\
\hline Total & 6786 & 7142 & 7144 & 7151 & 7359 & 7770 & 8014 \\
\hline
\end{tabular}


As the coordinates expressed in one geodetic datum can be easily transformed into another with a seven parameter transformation, most manufacturers of GPS receiver are now incorporating datum information into their software which enables users to receive positions referred to datum other than WGS-84 datum. Unfortunately many cases exist where a single transformation will not be accurate for a large regional datum.

The number of datums used to publish the charts is in the world greater than mentioned above in the case of UKHO (67) considerably. Actually in each receiver are available two global datums, WGS-84 and WGS-72, and $n$ local datums. This number $n$ depends on, first of all, the receiver type and kind and size of area in which the user relocates with this receiver. That's why in some receivers there are several datums only, in other several dozen, in professional units a few hundred. The receiver designed for the ship navigating around the world must have in its software all datums on which the charts of navigation bridge, often several thousand, were published.

\section{CONCLUSIONS}

- an increasing number of agreements between the GNSS providers guarantees the interoperability of all these systems and their signals,

- in the case of each GNSS the main goal of the international cooperation is to provide better compatibility and interoperability with existing and future SNS and augmentations (SBAS) for user benefit,

- L1C signal transmitted by the first QZSS Michibiki satellite is the first truly interoperable signal,

- for all users one official reference frame (time and datum) of all SNS and SBAS would be very desirable, but actually this demand cannot be realized,

- the time offset between the difference reference time SNS will be emitted in the navigation message of these systems. Various agreements already specify the time offsets and its provision to the user,

- each SNS use own geodetic coordinate reference frame, but for navigation purposes and most user requirements, the recent agreements between ITRF, GTRF, and WGS84 are sufficient and no coordinates transformation have to be applied,

- each level of GNSS integration - compatibility, interoperability and interchangeability - determines the kind of their utilization, adequately regulation, coordination and cooperation.

\section{REFERENCES}

Admiralty List of Radio Signals (ALRS, 2004-2010) The United Kingdom Hydrographic Office, vol.2

Gibbons G. (2011) GNSS Interoperability Not So Easy, After All, InsideGNSS, vol.6, No.1, $28-31$

Groves P. (2008) Principles of GNSS, Inertial, and Multisensor integrated navigation Systems, Artech House, Boston/London

GPS Receiver Survey (2011), GPS World, vol.22, No.1

Hahn J., Powers E. (2004) GPS and Galileo Timing Operability, Global Navigation Satellite System Conference, Rotterdam

Hein G.W (2006) GNSS Interoperability: Achieving a Global System of Systems or Does Everything Have to be the Same? InsideGNSS, Vol. 1, No.1 
Hofmann-Wellenhof B. et al. (2008) GNSS Global Navigation Satellite Systems GPS, GLONASS, Galileo \& more, Springer, Wien NewYork

Januszewski J. (2007) Compatibility and Interoperability of Satellite Navigation Systems, $11^{\text {th }}$ International Conference "Computer Systems Aided Science, Industry and Transport", Transcomp 2007, vol.1, 289-294

Januszewski J. (2010) "Time, its scales and part in satellite navigation systems", Scientific Journals Maritime University of Szczecin, No.20(92), 52-59

Kaplan E.D., Hegarty C.J. (2006) Understanding GPS Principles and Applications, Artech House, Boston/London

Liu W. et al. GNSS RF Compatibility Assessment Interference among GPS, Galileo, and Compass, GPS World, vol.21, No.12

Misra P., Enge P. (2006) Global Positioning System Signals, Measurements, and Performances, Ganga-Jamuna Press, Lincoln

Samama N. (2008) Global Technologies Technologies and Performance, John Viley \& Sons, New Jersey

Seeber G. (2003) Satellite Geodesy, de Gruyter, Berlin/New York

Turner D.A. (2010) GNSS Interoperability through International Cooperation, Institute of Navigation GNSS, Portland

$\underline{\text { www.congrex.nl }}$

$\underline{\text { www.galileo.cs.telespazio.it }}$

$\underline{\text { www.glonass-ianc.rsa.ru }}$

www.gpsworld.com

www.insidegnss.com

www.navcen.uscg.gov

Received: 2011-06-07,

Reviewed: 2011-07-11, by A. Nowak,

Accepted: 2011-07-14. 